\section{LIVE BRAIN-COMPUTER CINEMA PERFORMANCE}

Polina Zioga

The majority of the applications of Brain-Computer Interfaces (BCIs) in the arts and entertainment use the brain activity of a single participant, although an increasing number involve the interaction of more than one user.

This dissertation investigates the design and implementation of multi-brain electroencephalography (EEG)-based BCIs in the context of live cinema and mixed-media performances. The aim is to identify the interdisciplinary challenges involved and to develop an effective model for the simultaneous multi-brain interactions of performers and audiences.

By combining scientific and practice-based methodologies, a new passive multi-brain EEG-based BCI system was developed and implemented in Enheduanna-A Manifesto of Falling, the first demonstration of a live brain-computer cinema performance (CCA Glasgow, July 2015). This new work enabled the simultaneous, real-time interactionwith the use of EEG-based BCIs - of more than two participants, including both a performer and members of the audience, in the context of a mixed-media performance. The analysis of the participants' data reveals a correlation between the elements of the performance that they identified as most special and their indicators of attention and emotional engagement, proving the efficiency of the interaction design, the importance of the directing strategy, dramaturgy and narrative structure. Accordingly, the original contributions of the research include the new passive multi-brain EEG-based BCI system, the live braincomputer cinema performance, as a novel format of performative work and as a complete combination of creative and scientific solutions.

Polina Zioga: <info@polina-zioga.com>.

PhD thesis, Glasgow School of Art, U.K., 2017.

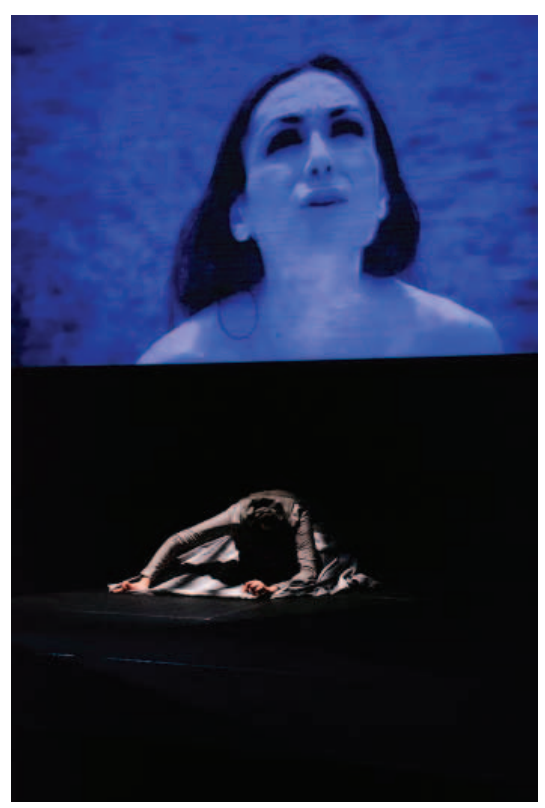

EnheduannaA Manifesto of Falling, live brain-computer cinema performance at CCA Glasgow, 30-31 July 2015. (C) Polina Zioga Photo: Catherine M. Weir.) 